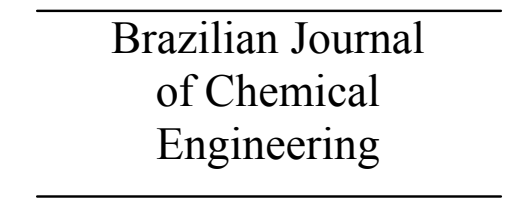

ISSN 0104-6632

Printed in Brazil

www.abeq.org.br/bjche

Vol. 27, No. 02, pp. 357 - 367, April - June, 2010

\title{
APPLICATION OF BIOWASTE (WASTE GENERATED IN BIODIESEL PLANT) AS AN ADSORBENT FOR THE REMOVAL OF HAZARDOUS DYE - METHYLENE BLUE - FROM AQUEOUS PHASE
}

\author{
R. Gottipati ${ }^{1 *}$ and S. Mishra ${ }^{2}$ \\ ${ }^{1,2}$ Department of Chemical Engineering, National Institute of Technology, \\ Phone: 91-6612462255, Fax: 91-6612462999, Rourkela, 769008, Orissa, India. \\ E-mail: ramakrishnagottipati@gmail.com
}

(Submitted: August 16, 2009 ; Revised: March 28, 2010 ; Accepted: March 31, 2010)

\begin{abstract}
Solid waste (SW) from a biodiesel plant has been successfully used for the removal of the hazardous cationic water soluble dye - methylene blue (MB) - from an aqueous phase. Batch adsorption studies were carried out by monitoring the $\mathrm{pH}$, amount of adsorbent, initial dye concentration and contact time. Attempts have also been made to monitor the adsorption process through Langmuir, Freundlich, Temkin and D-R adsorption isotherm models. Relevant thermodynamic parameters were calculated and it was found that the adsorption process was exothermic and feasible at low temperatures. The nature and randomness of the adsorption process was determined by calculating the thermodynamic parameters such as Gibbs free energy $\left(\Delta \mathrm{G}^{0}\right)$, change in entropy $\left(\Delta \mathrm{S}^{0}\right)$ and heat of adsorption $\left(\Delta \mathrm{H}^{\circ}\right)$. The kinetics of the adsorption indicates that the process is pseudo-second-order and also reveals the involvement of bulk diffusion and intraparticle diffusion mechanisms.

Keywords: Methylene blue; Adsorption; Thermogravimetry; Kinetics; Error analysis.
\end{abstract}

\section{INTRODUCTION}

Dye effluents from dyestuff manufacturing and textile industries exhibit toxic effects on microbial populations and can be toxic and/or carcinogenic to mammalian animals (Purkait et al., 2007). On inhaling, symptoms such as difficulties in breathing, vomiting, dermatitis, diarrhea and cancer can occur for human beings (Bilal, 2004; Dursun et al., 2007; Cengiz and Cavas, 2008; Al-Qodah et al., 2007; Namasivayam and kavitha, 2002). By design, these dyes are highly stable molecules, made to resist degradation by light, chemical, biological and other exposures (EI-Qada et al., 2008). The world's annual production of the dyes is over $7 \times 10^{5}$ tonnes (Dhaneshvar et al., 2007). Dyes such as methylene blue (MB) have great application in printing press, textile industries etc. The largest consumer of the dyes is the textile industry, accounting for two thirds of its market. Annually, $12 \%$ of the synthetic textile dyes used are lost to wastewater streams (Allen and Koumanova, 2003). They are difficult to decolorize due to their complex structure, synthetic origin and recalcitrant nature, which make it obligatory to remove them from industrial effluents before being disposed into hydrological systems (Brown, 1987).

Thus, colour removal is one of the daunting tasks faced by the textile finishing, dye manufacturing, pulp and paper, kraft bleaching and tannery industries. Several methods have been employed to remove dyes from the waste water such as physical and chemical processes. Amongst the various commercial processes, colour removal using activated carbon has great potential (Ho and McKay,

*To whom correspondence should be addressed 
1998; MacKay and Allen, 1980; Hubbard, 2003; Perrich, 1981). However, due to the high cost of activated carbon, adsorption using cheaper materials are preferable. Several studies have shown that numerous low cost materials like potato starch (Thakkar et al., 2006), kaolinite (Ghosh and Bhattacharyya, 2002), jordanian tripoli (Alzaydien, 2009) and activated carbon prepared from periwinkle shells (Bello et al., 2008) can be successfully applied for the removal of $\mathrm{MB}$ from aqueous solution. However, only few of them could be employed effectively to remove dyes from waste water streams.

In the present study, the residue of Madhuca indica seeds collected from a biodiesel plant has been used effectively as an adsorbent for the removal of MB from aqueous solution. India produces about 5,00,000 metric tonnes of Madhuca indica seeds annually. It is a common tropical tree that can grow up to an average height of $18 \mathrm{~m}$. Each tree can produce $5-200 \mathrm{~kg}$ of seeds depending on the age and size of tree. Production of one litre of oil requires $4 \mathrm{~kg}$ of seeds, leaving $3.5 \mathrm{~kg}$ of residue (oil cake), which is $75 \%$ of the total seed weight (Mishra et al., 2009). Usage of some types of oil cakes as animal feed or fertilizer is not recommended because of the low protein content. Moreover, due to the increasing demand for biodiesel, the load of oil cake has been increased. About two tonnes of oil cake are dumped as a waste for every tonne of biodiesel production. Novel technologies are needed to deal with this type of oil cake to convert it into other useful forms. Thus, throughout this paper we tried to explore the potential of biowaste (Madhuca indica oil cake) for the removal of methylene blue dye from an aqueous phase.

\section{MATERIALS AND METHODS}

\section{Adsorbent Preparation}

The solid waste (SW) was collected from the local biodiesel plant. Size reduction of the SW was achieved through mechanical grinding and uniform size of material was obtained by sieving through $18+52$ (B.S.S.) mesh. After washing with distilled water, SW was treated with dilute $\mathrm{HCl}(0.1 \mathrm{~N})$ for 24 $\mathrm{h}$ to oxidize the organic impurities. Finally it was washed with distilled water until no further change in $\mathrm{pH}$ of the drained water was noted. The moisture was removed by keeping the material in an oven at $70 \pm$ $2^{\circ} \mathrm{C}$ and subsequently cooled and stored in an air tight container for further use.

The material was characterized (Table 1) according to standard procedures. The zero point charge $\left(\mathrm{pH}_{\mathrm{pzc}}\right)$ was determined by using a Zetasizer (Malvern, Nano ZS). Proximate analysis of SW was carried out by using a thermogravimetrc analyzer (TGA) (Shimadzu, DTG$60 \mathrm{H})$ (Sricharoenchaikul et al., 2008). The experimental conditions for TGA were - initial temperature: $35^{\circ} \mathrm{C}$; final temperature: $700^{\circ} \mathrm{C}$; heating rate: $10^{\circ} \mathrm{C} \mathrm{m^{-1 }}$ and nitrogen flow: $35 \mathrm{ml} / \mathrm{min}$. Cellulose and lignin contents were determined by using the anthrone reagent test and kappa number method, respectively (Mission et al., 2009).

The specific surface area was determined by the Brunauer, Emmett and Teller (BET) equation using adsorption isotherms of nitrogen. An automated adsorption apparatus, Autosorb-1 (Quantachrome), was used for the determination of nitrogen adsorption isotherms at $-196^{\circ} \mathrm{C}$. The surface functional groups of the adsorbent were ivestigated by FT-IR (PerkinElmer) at a resolution of $4 \mathrm{~cm}^{-1}$ in the range of 400 $4000 \mathrm{~cm}^{-1}$ equipped with IR source.

\section{Adsorbate}

The adsorbate, methylene blue (MB) [3,7bis(Dimethylamino)-phenazathionium chloride tetramethylthionine chloride; chemical formula $=$ $\mathrm{C}_{16} \mathrm{H}_{18} \mathrm{~N}_{3} \mathrm{CIS}$; molecular weight $=319.85 \mathrm{~g} \mathrm{~mol}^{-1}$; nature $=$ basic blue] was obtained from M/s Merk and its stock solution was prepared with doubledistilled water. Experimental solutions of the desired concentrations were obtained by successive dilutions with distilled water.

Table 1: Characterization of adsorbent (Madhuca indica oil cake).

\begin{tabular}{|l|c|l|r|}
\hline Property/Composition & Value & Property/Composition & Value \\
\hline Moisture (\%) & 6.5 & Cellulose (\%) & 27.94 \\
Volatile Matter (\%) & 68.3 & Density $\left(\mathrm{g} \mathrm{cc}^{-1}\right)$ & 0.3482 \\
Fixed carbon (\%) & 18.4 & BET surface area $\left(\mathrm{m}^{2} \mathrm{~g}^{-1}\right)$ & 28.24 \\
Ash (\%) & 6.8 & $\mathrm{pH}_{\mathrm{pzc}}$ & 6.2 \\
Lignin (\%) & 14.86 & & \\
\hline
\end{tabular}




\section{Analytical Measurements}

Different concentrations of dye solutions were determined by finding the absorbance at the characteristic wavelength using a UV/Vis spectrophotometer (JASCO UV/Vis-550). Absorbance of the standard dye solution was measured at different wavelengths and the wavelength corresponding to maximum absorbance $\left(\lambda_{\max }\right)$ was found to be $661 \mathrm{~nm}$. Using these absorbance values, a calibration curve was plotted from which the different concentrations of dye solutions were found.

\section{Batch Adsorption Studies}

The batch adsorption experiments were conducted at $303 \mathrm{~K}$ to study the effect of important parameters like $\mathrm{pH}$, adsorbent dose $(\mathrm{m})$, contact time $(\mathrm{t})$ and initial dye concentration $\left(\mathrm{C}_{\mathrm{o}}\right)$ on the adsorptive removal of $\mathrm{MB}$. For each run, $100 \mathrm{ml}$ of $\mathrm{MB}$ solution of known concentration, initial $\mathrm{pH}$ and amount of adsorbent were taken in a $250 \mathrm{ml}$ conical flask. This mixture was agitated in a temperature controlled environmental orbital shaker incubator (DENEB Instruments) at a constant speed of $120 \mathrm{rpm}$ at $303 \mathrm{~K}$. All the samples were centrifuged (Hettich - Zentrifugen, UNIVERSAL $320 \mathrm{R}$ ) at $8000 \mathrm{rpm}$ for $10 \mathrm{~min}$ and analyzed spectrophotometrically for the residual $\mathrm{MB}$ concentration. The effect of initial $\mathrm{pH}$ on dye removal was studied over a $\mathrm{pH}$ range of 2-8 and the sample's $\mathrm{pH}$ was adjusted by the addition of $0.1 \mathrm{M} \mathrm{HCl}$ or $\mathrm{NaOH}$. To find the effect of adsorbent dose, a $100 \mathrm{ml}$ dye solution of known concentration was contacted with different amounts of MOC until equilibrium was achieved. Kinetics of the dye adsorption was determined by analyzing the removal of dye at different time intervals. For adsorption isotherms, different concentrations of MB solutions were contacted with known amounts of adsorbent until the equilibrium was attained. The effect

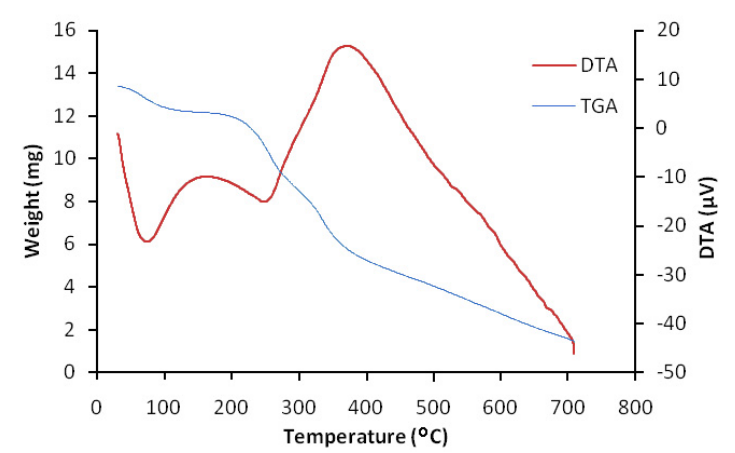

Figure 1: TGA and DTA curves of $\mathrm{SW}$ in nitrogen atmosphere, heating rate: $10^{\circ} \mathrm{C} \mathrm{min}^{-1}$. of temperature on adsorption was found by determining the adsorption isotherms at 303,313 and $323 \mathrm{~K}$.

\section{RESULTS AND DISCUSSION}

\section{Thermogravimetric Analysis (TGA)}

Fig. 1 shows the TGA and DTA curves of the SW in a $\mathrm{N}_{2}$ atmosphere. In the initial stage, the minor weight loss was attributed to desorption of moisture as bound water on the surface and pores of the sample. The sudden increase in the weight loss after $200^{\circ} \mathrm{C}$ was due to the release of volatiles. The DTA curve shows the exothermic and endothermic reactions of SW at their respective temperatures.

\section{FT-IR Analysis}

Various organic functionalities disappeared and some new functional groups are incorporated (see IR spectra of the samples in Fig. 2) onto the SW after adsorption of MB. The bands around $3288 \mathrm{~cm}^{-1}$ can be assigned to stretching vibrations of $(\mathrm{HN}-\mathrm{H})$ and $(=\mathrm{C}-\mathrm{H})$ and the bands at $2924 \mathrm{~cm}^{-1}$ and 1450 $\mathrm{cm}^{-1}$ indicate the presence of $(\mathrm{C}-\mathrm{H})$ group. The observed bands at $1670 \mathrm{~cm}^{-1}$ are of strong stretching vibrations of $(\mathrm{C}=\mathrm{O})$ and the stretching of $(\mathrm{C}-\mathrm{O})$ groups is found at $1234 \mathrm{~cm}^{-1}$. The bands at $1035 \mathrm{~cm}^{-}$ ${ }^{1}(\mathrm{C}-\mathrm{O})$ can be assigned to esters. A split band can be observed at $2856 \mathrm{~cm}^{-1}$ due to the presence of acidic hydroxyl $(\mathrm{O}-\mathrm{H})$ groups. The main change observed after adsorption of dye was splitting of strong stretching of $(\mathrm{C}=\mathrm{O})$ into small splits. This splitting is not only due to the adsorption of dye but also due to the electrostatic interactions between MB and adsorbent.

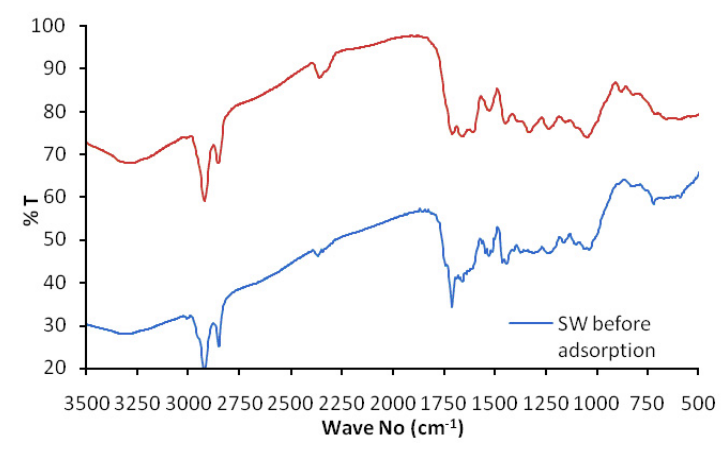

Figure 2: FT-IR spectra of SW before and after adsorption of $\mathrm{MB}$. 


\section{Batch Adsorption Studies}

\section{Effect of pH}

Methylene blue dye adsorption on SW is greatly influenced by the initial $\mathrm{pH}$ of the solution. Process $\mathrm{pH}$ greatly affects the surface binding sites of biomaterials and the ionization process of dye molecules. In order to optimize the $\mathrm{pH}$, adsorption of the dye over $\mathrm{SW}$ was carried out in the $\mathrm{pH}$ range 2 to 8. From Fig. 3, when the $\mathrm{pH}$ increases from 2 to 4 there is a steep increase in adsorption of methylene blue and no significant change in the amount adsorbed by further increase of $\mathrm{pH}$ up to 8 . Similar findings were reported by many authors so far (Hamdaoui, 2006; Wang et al., 2005; Dogan et al., 2004; Bhattacharyya and Sharma, 2005). The $\mathrm{pH}$ trend observed clearly indicates that the maximum adsorption of methylene blue takes place at both neutral and slightly basic $\mathrm{pH}$. This can be explained by the electrostatic interaction of methylene blue (because of its cationic structure) with negatively charged surface of the SW. The protonation of MB takes place in a highly acidic medium, while on the other hand, with decrease in acidity of the solution the dye becomes deprotonated. Another possibility can be the development of positive charge on the adsorbent in highly acidic solution, which inhibits the adsorption of dye, resulting in low adsorption. However, on increasing the basicity, the uptake of the dye increases due to a change in its polarity.

\section{Effect of Adsorbent Dose (m)}

To determine the effect of amount of adsorbent on dye adsorption, different amounts of adsorbent (ranging from $1-9 \mathrm{~g} \mathrm{l}^{-1}$ ) were added at a particular

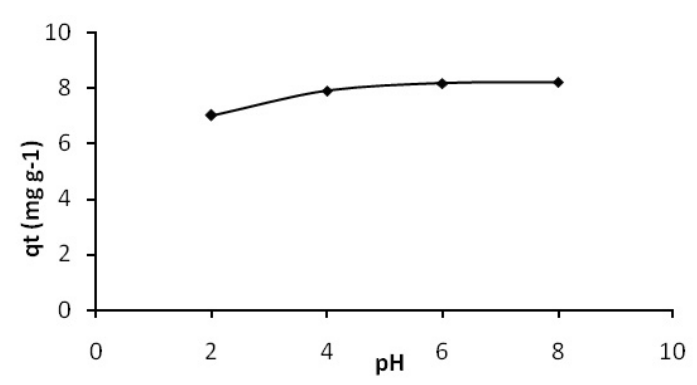

Figure 3: Effect of $\mathrm{pH}$ on uptake of methylene blue $(\mathrm{MB})$ by $\mathrm{SW}$ at $30^{\circ} \mathrm{C}$ (dye concentration $=$ $25 \mathrm{mg} \mathrm{L}^{-1}$, adsorbent dose $\left.=6 \mathrm{~g} \mathrm{~L}^{-1}\right)$. concentration and $\mathrm{pH}$ of the solution. It was observed that, with increase of amount of adsorbent, adsorption of dye also increases and became almost constant after $6 \mathrm{~g} \mathrm{l}^{-1}$. An increase in the adsorption with the adsorbent dosage can be attributed to greater surface area and the availability of more adsorption sites. At $\mathrm{m}<6 \mathrm{~g} \mathrm{l}^{-1}$, the adsorbent surface becomes saturated with $\mathrm{MB}$ and the residual concentration in the solution is high. At $\mathrm{m}>6 \mathrm{~g} \mathrm{l}^{-1}$, the removal efficiency becomes almost constant and the incremental MB removal becomes very low, as the concentrations of the MB on the surface of adsorbent and in the solution come to equilibrium with each other.

\section{Effect of Contact Time (t) and Initial Dye Concentration $\left(\mathbf{C}_{0}\right)$}

In the contact time studies, dye uptake capacities were determined at a fixed amount of adsorbent $\left(6 \mathrm{~g}^{-1}\right)$ and initial dye concentrations $\left(\mathrm{C}_{\mathrm{o}}\right)$ ranging from 25 to $100 \mathrm{mg} \mathrm{l}^{-1}$. Fig. 4 illustrates that the adsorption of the dye is rapid in the initial $15 \mathrm{~min}$; thereafter, the rise in adsorption rate decreased gradually and reached equilibrium within $1.5 \mathrm{~h}$. In the first $15 \mathrm{~min}$ of contact, almost $85 \%$ of the dye was adsorbed, while only $13 \%$ adsorption occurred in the next $2 \mathrm{~h}$. From the figure, it is observed that the amount of MB adsorbed per unit mass of SW $\left(\mathrm{q}_{\mathrm{e}}\right)$ increased with increase in $\mathrm{C}_{0}$, although percentage removal of dye decreased with the increase of $\mathrm{C}_{0}$. The $\mathrm{C}_{\mathrm{o}}$ provides the necessary driving force to overcome the resistance to the mass transfer of MB between the aqueous and the solid phases. Therefore, an increase in $\mathrm{C}_{\mathrm{o}}$ of $\mathrm{MB}$ enhances the adsorption uptake of SW. The rate of adsorption also increases with the increase in $\mathrm{C}_{\mathrm{o}}$ due to the increase in driving force (Mittal et al., 2008).

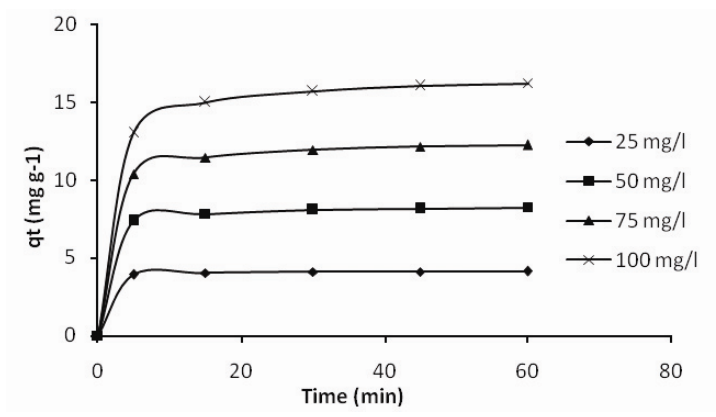

Figure 4: Effect of contact time on the removal of $\mathrm{MB}\left(\mathrm{T}=30^{\circ} \mathrm{C}, \mathrm{C}_{\mathrm{o}}=25,50,75\right.$, and $100 \mathrm{mg}$ $\left.\mathrm{L}^{-1}, \mathrm{~m}=6 \mathrm{~g} \mathrm{~L}^{-1}\right)$. 


\section{Adsorption Isotherms}

Various isotherms like Langmuir, Freundlich, D$\mathrm{R}$ and Temkin have been used to describe the equilibrium characteristics of adsorption.

\section{Langmuir and Freundlich Adsorption Isotherms}

The Freundlich isotherm is derived by assuming a heterogeneous surface with a non-uniform distribution of heat of adsorption over the surface. In Langmuir theory, the basic assumption is that sorption takes place at specific homogeneous sites within the adsorbent. The linearized forms of Langmuir and Freundlich isotherms are given by Equations (1) and (2), respectively:

$$
\frac{1}{\mathrm{q}}=\frac{1}{\mathrm{Q}_{\max }}+\frac{1}{\mathrm{bQ}_{\max }} \frac{1}{\mathrm{C}_{\mathrm{e}}}
$$

$\log \mathrm{q}=\log \mathrm{K}+\frac{1}{\mathrm{n}} \log \mathrm{C}_{\mathrm{e}}$

where $\mathrm{C}_{\mathrm{e}}$ is the concentration of $\mathrm{MB}$ solution at equilibrium $\left(\mathrm{mg} \mathrm{l}^{-1}\right), \mathrm{q}$ is the amount of MB adsorbed at equilibrium $\left(\mathrm{mg} \mathrm{g}^{-1}\right), \mathrm{Q}_{\max }$ is the maximum adsorption capacity of the $\mathrm{MB}-\mathrm{SW}$ system $\left(\mathrm{mg} \mathrm{g}^{-1}\right)$, $\mathrm{b}$ is a constant related to the energy, and $\mathrm{K}$ and $\mathrm{n}$ are constants that are considered to be the relative indicators of adsorption capacity and adsorption intensity. Langmuir and Freundlich adsorption isotherm constants at 30,40 and $50^{\circ} \mathrm{C}$ for $\mathrm{MB}$ adsorption over MOC were calculated (Table 2). The rate of uptake of dye by SW was found to decrease with the increase in temperature, indicating the process to be exothermic in nature (Gupta et al., 2006). Using these data thermodynamic parameters such as Gibb's free energy $\left(\Delta \mathrm{G}^{\circ}\right)$, change in entropy $\left(\Delta \mathrm{S}^{\circ}\right)$, and change in enthalpy $\left(\Delta \mathrm{H}^{\circ}\right)$ at different temperatures were calculated (Table 3 ) using the following equations.

$$
\begin{aligned}
& \Delta \mathrm{G}^{\circ}=-\mathrm{RT} \ln \mathrm{b} \\
& \Delta \mathrm{H}^{\circ}=-\mathrm{R} \frac{\mathrm{T}_{2} \mathrm{~T}_{1}}{\mathrm{~T}_{2}-\mathrm{T}_{1}} \ln \frac{\mathrm{b}_{2}}{\mathrm{~b}_{1}} \\
& \Delta \mathrm{S}^{\circ}=\frac{\Delta \mathrm{H}^{\circ}-\Delta \mathrm{G}^{\circ}}{\mathrm{T}}
\end{aligned}
$$

where $b, b_{1}$ and $b_{2}$ are the equilibrium constants at temperatures of 30,40 and $50^{\circ} \mathrm{C}$, respectively. The negative values of free energy suggest the feasibility of the process, while positive values of entropy change and negative values of enthalpy show increased randomness and the exothermic nature of the ongoing adsorption process, respectively.

The thermodynamic parameters presented in Table 3 were calculated using the Freundlich isotherm data. The adsorption process was better fitted to the Freundlich isotherm than that of

\begin{tabular}{|c|c|c|c|}
\hline \multicolumn{4}{|c|}{ Langmuir constants } \\
\hline $\mathbf{T}(\mathbf{K})$ & $Q_{\max }\left(\mathrm{mg} \mathrm{g}^{-1}\right)$ & b $\left(1 \mathrm{mg}^{-1}\right)$ & $\mathbf{R}^{2}$ \\
\hline 303 & 40 & 0.294 & 0.998 \\
\hline 313 & 31.25 & 0.421 & 0.998 \\
\hline 323 & 29.42 & 0.515 & 0.996 \\
\hline \multicolumn{4}{|c|}{ Freundlich constants } \\
\hline $\mathbf{T}(\mathbf{K})$ & $\mathbf{K}$ & $1 / \mathbf{n}$ & $\mathbf{R}^{2}$ \\
\hline 303 & 8.65 & 0.766 & 0.994 \\
\hline 313 & 8.65 & 0.711 & 0.993 \\
\hline 323 & 7.71 & 1.035 & 0.936 \\
\hline
\end{tabular}
Langmuir.

Table 2: Langmuir and Freundlich constants for the removal of MB (adsorbent dose $(\mathrm{m})=6 \mathrm{~g} \mathrm{~L}^{-1}, \mathrm{pH}=7$ ).

Table 3: Thermodynamic parameters for the uptake of MB (adsorbent dose $(\mathrm{m})=6 \mathrm{~g} \mathrm{~L}^{-1}, \mathrm{pH}=7$ )

\begin{tabular}{|c|c|c|c|c|}
\hline \multicolumn{3}{|c|}{$-\Delta \mathbf{G}^{\mathbf{0}}\left(\mathbf{J ~ m o l}^{-\mathbf{1}}\right)$} & \multirow{2}{*}{$-\Delta \mathbf{H}^{\mathbf{0}}\left(\mathbf{J ~ m o l}^{-\mathbf{1}}\right)$} & \multirow{2}{*}{$\Delta \mathbf{S}^{\mathbf{0}}\left(\mathbf{J ~ m o l}^{-\mathbf{1}} \mathbf{K}^{-\mathbf{1}}\right)$} \\
\hline $303 \mathrm{~K}$ & $313 \mathrm{~K}$ & $323 \mathrm{~K}$ & 4628.9 & 2.82 \\
\cline { 5 - 5 } & 5511.59 & 5539.8 & & \\
\hline
\end{tabular}


Table 4: Temkin and D-R constants for MB - SW system.

\begin{tabular}{|c|c|c|c|}
\hline \multicolumn{4}{|c|}{ Temkin constants } \\
\hline $\mathbf{T}(\mathbf{K})$ & $\mathbf{B}_{1}$ & $K_{t}\left(L_{m g}^{-1}\right)$ & $\mathbf{R}^{2}$ \\
\hline 303 & 5.5891 & 6.0589 & 0.996 \\
\hline 313 & 6.4219 & 4.4110 & 0.970 \\
\hline 323 & 9.5289 & 2.4243 & 0.976 \\
\hline \multicolumn{4}{|c|}{ Dubinin-Radushkevich constants } \\
\hline $\mathbf{T}(\mathrm{K})$ & $\mathrm{q}_{\mathrm{s}}\left(\mathrm{mg} \mathrm{g}^{-1}\right)$ & E $\left(\mathrm{kJ} \mathrm{mol}^{-1}\right)$ & $\mathbf{R}^{2}$ \\
\hline 303 & 15.4653 & 2.1035 & 0.976 \\
\hline 313 & 15.4963 & 1.9687 & 0.956 \\
\hline 323 & 20.3138 & 1.4086 & 0.986 \\
\hline
\end{tabular}

Temkin and Dubinin-Radushkevich (D-R) Adsorption Isotherms

Thermodynamic data (Table 4) were also verified through Temkin and Dubinin - Radushkevich (D-R) isotherm models to derive the possibility of interactions among adsorbate particles and also to estimate the type of adsorption reaction. The Temkin isotherm assumes that the heat of adsorption decreases linearly due to adsorbent - adsorbate interactions and adsorption is characterized by a uniform distribution of binding energies, up to the maximum binding energy (Temkin and Pyzhev, 1940; Kim et al., 2004).

The Temkin isotherm is given as:

$\mathrm{q}_{\mathrm{e}}=\frac{\mathrm{RT}}{\mathrm{b}} \ln \mathrm{K}_{\mathrm{t}} \mathrm{C}_{\mathrm{e}}$

which can be linearized as:

$\mathrm{q}_{\mathrm{e}}=\mathrm{B}_{1} \ln \mathrm{K}_{\mathrm{t}}+\mathrm{B}_{1} \ln \mathrm{C}_{\mathrm{e}}$

where

$\mathrm{B}_{1}=\frac{\mathrm{RT}}{\mathrm{b}}$

$\mathrm{K}_{\mathrm{t}}$ is the equilibrium binding constant corresponding to the maximum binding energy and $\mathrm{B}_{1}$ is a constant related to the heat of adsorption.

The Dubinin - Radushkevich (D-R) (Dubinin and Radushkevich, 1947) isotherm is given as:

$\mathrm{q}_{\mathrm{e}}=\mathrm{q}_{\mathrm{s}} \exp \left(-\mathrm{B} \varepsilon^{2}\right)$

where $\mathrm{q}_{\mathrm{s}}$ is the $\mathrm{D}-\mathrm{R}$ constant and $\varepsilon$ can be correlated as:

$$
\varepsilon=\mathrm{RT} \ln \left(1+\frac{1}{\mathrm{C}_{\mathrm{e}}}\right)
$$

The mean free energy $\mathrm{E}$ of sorption per molecule of sorbate can be calculated from the constant B and is related by the following relationship (Hasany and Chaudhary, 1996).
$\mathrm{E}=\frac{1}{\sqrt{2 \mathrm{~B}}}$

\section{Adsorption Kinetic Study}

To investigate the adsorption process of $\mathrm{MB}$ on MOC different kinetic models like pseudo-firstorder, pseudo-second-order, Bangham and intraparticle diffusion were used.

\section{Pseudo-First-Order Model}

The pseudo-first-order equation is given as (Lagergren, 1898):

$\log \left(q_{e}-q_{t}\right)=\log q_{e}-\frac{k_{f}}{2.303} t$

where $q_{t}$ is the amount of adsorbate adsorbed at time $\mathrm{t}\left(\mathrm{mg} \mathrm{g}^{-1}\right), \mathrm{q}_{\mathrm{e}}$ is the adsorption capacity at equilibrium $\left(\mathrm{mg} \mathrm{g}^{-1}\right), \mathrm{k}_{\mathrm{f}}$ is the pseudo-first-order rate constant $\left(\mathrm{min}^{-1}\right)$ and $t$ is the contact time (min). The values of $\mathrm{k}_{\mathrm{f}}$ determined from the plot of $\log \left(\mathrm{q}_{\mathrm{e}}-\mathrm{q}_{\mathrm{t}}\right)$ against $\mathrm{t}$ are presented in Table 5 .

\section{Pseudo-Second-Order Model}

The pseudo-second-order model is represented as (Ho and McKay, 1999):

$\frac{\mathrm{t}}{\mathrm{q}_{\mathrm{t}}}=\frac{1}{\mathrm{kq}_{\mathrm{e}}^{2}}+\frac{\mathrm{t}}{\mathrm{q}_{\mathrm{t}}}$

where $\mathrm{k}$ is the pseudo-second-order rate constant ( $\mathrm{g}$ $\left.\mathrm{mg}^{-1} \mathrm{~min}^{-1}\right)$. The initial sorption rate, $\mathrm{h}\left(\mathrm{mg} \mathrm{g}^{-1} \mathrm{~min}^{-1}\right)$, is defined as

$\mathrm{h}=\mathrm{kq}_{\mathrm{e}}^{2}$

From the plot of $t / q_{t}$ versus $t$ (Fig. 5), $q_{e}$ is obtained from the slope and $\mathrm{h}$ is obtained from the intercept. Since $\mathrm{q}_{\mathrm{e}}$ is known, $\mathrm{k}$ can be determined from the value of $h$ and the values of $k, q_{e}$ and $h$ are shown in Table 6 .

Compared to the pseudo-first-order kinetic model, $\mathrm{q}_{\mathrm{e}, \text { exp }}$ and the $\mathrm{q}_{\mathrm{e}, \mathrm{cal}}$ values of the pseudo- 
second-order kinetic model are very close to each other. The calculated correlation coefficients are also closer to unity for pseudo-second-order kinetics than that for the pseudo-first-order kinetic model. Therefore, the adsorption can be approximated more appropriately by the pseudo-second-order kinetic model than the first-order kinetic model for the adsorption of $\mathrm{MB}$ by $\mathrm{SW}$.

\section{Bangham's Equation}

Bangham's equation (Aharoni et al., 1979) is represented as: $\log \log \left(\frac{\mathrm{C}_{0}}{\mathrm{C}_{0}-\mathrm{q}_{\mathrm{t}} \mathrm{m}}\right)=\log \left(\frac{\mathrm{k}_{0} \mathrm{~m}}{2.303 \mathrm{~V}}\right)+\alpha \log (\mathrm{t})$

where $\mathrm{V}$ is the volume of the solution $(\mathrm{ml})$, and $\alpha$ and $\mathrm{k}_{\mathrm{o}}$ are constants. The plot obtained according to Eq. (12) is not satisfactorily linear. This shows that the bulk diffusion of MB into the pores of SW was not the only rate limiting step (Tutem et al., 1998) and it may be due to the both film and pore diffusion. The kinetic parameters are presented in Table 7.

Table 5: Pseudo-first-order parameters for the removal of $\mathrm{MB}$ by $\mathrm{SW}\left(\mathrm{T}=303 \mathrm{~K}, \mathrm{C}_{0}=25,50,75\right.$ and $\left.100 \mathrm{mg} \mathrm{L}^{-1}, \mathrm{~m}=6 \mathrm{~g} \mathrm{~L}^{-1}\right)$.

\begin{tabular}{|c|c|c|c|c|}
\hline \multicolumn{5}{|c|}{ Pseudo-first-order model } \\
\hline $\mathbf{C}_{\mathbf{0}} \mathbf{( \mathbf { m g ~ L } ^ { - \mathbf { 1 } } )}$ & $\mathbf{k}_{\mathbf{f}} \mathbf{( \mathbf { m i n } ^ { \mathbf { - 1 } } )}$ & $\mathbf{q}_{\mathbf{e}, \mathbf{e x p}} \mathbf{( \mathbf { m g ~ g } ^ { - 1 } )}$ & $\mathbf{q}_{\mathbf{e , c a l}} \mathbf{( \mathbf { m g ~ g } ^ { \mathbf { 1 } } )}$ & $\mathbf{R}^{\mathbf{2}}$ \\
\hline 25 & 0.0576 & 4.11 & 0.2182 & 0.995 \\
50 & 0.0552 & 8.22 & 0.9057 & 0.977 \\
75 & 0.0691 & 12.24 & 2.4434 & 0.977 \\
100 & 0.0599 & 16.28 & 3.4914 & 0.995 \\
\hline
\end{tabular}

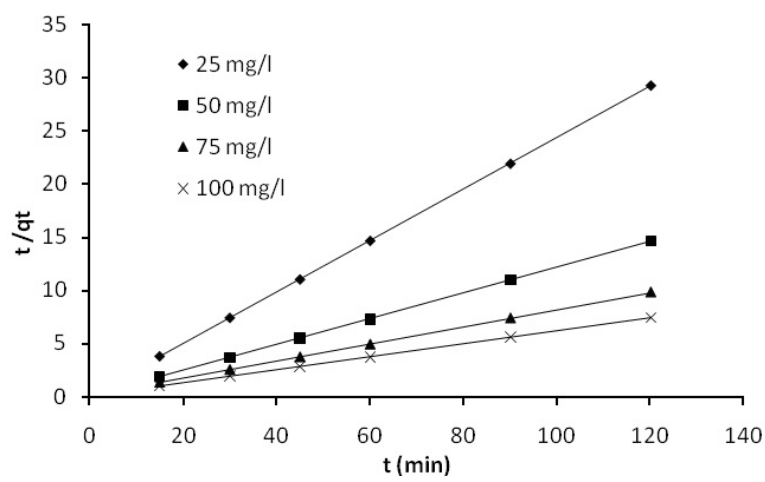

Figure 5: Pseudo-second-order kinetics plot for the removal of $\mathrm{MB}$ by SW $\left(\mathrm{T}=303 \mathrm{~K}, \mathrm{C}_{\mathrm{o}}=25,50,75\right.$ and $\left.100 \mathrm{mg} \mathrm{L}^{-1}, \mathrm{~m}=6 \mathrm{~g} \mathrm{~L}^{-1}\right)$.

Table 6: Pseudo-second-order parameters for the removal of $\mathrm{MB}$ by SW $\left(T=303 \mathrm{~K}, \mathrm{C}_{0}=25,50,75\right.$ and $\left.100 \mathrm{mg} \mathrm{L}^{-1}, \mathrm{~m}=6 \mathrm{~g} \mathrm{~L}^{-1}\right)$.

\begin{tabular}{|c|c|c|c|c|c|}
\hline \multicolumn{6}{|c|}{ Pseudo-second-order } \\
\hline $\mathrm{C}_{0}\left(\mathrm{mg} \mathrm{l}^{-1}\right)$ & $k\left(g g^{-1} \min ^{-1}\right)$ & $h\left(\mathrm{mg} \mathrm{g}^{-1} \min ^{-1}\right)$ & $q_{e, e x p}\left(m g ~ g ~^{-1}\right)$ & $q_{e, c a l}\left(m g ~ g^{-1}\right)$ & $\mathbf{R}^{2}$ \\
\hline 25 & 0.9374 & 15.83 & 4.11 & 4.12 & 0.999 \\
\hline 50 & 0.8202 & 55.96 & 8.22 & 8.26 & 0.999 \\
\hline 75 & 0.7669 & 116.79 & 12.24 & 12.35 & 0.997 \\
\hline 100 & 0.7382 & 204.88 & 16.28 & 16.67 & 0.993 \\
\hline
\end{tabular}

Table 7: Bangham's parameters for the removal of $\mathrm{MB}$ by $\mathrm{SW}\left(\mathrm{T}=303 \mathrm{~K}, \mathrm{C}_{\mathrm{o}}=25,50,75\right.$ and $\left.100 \mathrm{mg} \mathrm{L}^{-1}, \mathrm{~m}=6 \mathrm{~g} \mathrm{~L}^{-1}\right)$.

\begin{tabular}{|c|c|c|c|}
\hline \multicolumn{4}{|c|}{ Bangham's model } \\
\hline $\mathrm{C}_{0}\left(\mathrm{mg} \mathrm{l}^{-1}\right)$ & $\mathbf{k}_{\mathbf{0}}$ & $\alpha$ & $\mathbf{R}^{2}$ \\
\hline 25 & 42.3977 & 0.1145 & 0.82 \\
\hline 50 & 29.3388 & 0.1917 & 0.80 \\
\hline 75 & 23.7389 & 0.2228 & 0.86 \\
\hline 100 & 21.431 & 0.2314 & 0.91 \\
\hline
\end{tabular}




\section{Intra-Particle Diffusion}

The intra-particle diffusion model (Weber and Morris, 1963), which explores the effect of intraparticle diffusion resistance on adsorption, can be represented as:

$$
\mathrm{q}_{\mathrm{t}}=\mathrm{k}_{\mathrm{id}} \mathrm{t}^{1 / 2}+\mathrm{I}
$$

where $\mathrm{k}_{\mathrm{id}}$ is the rate constant and values of I (Table 8) give an idea about the boundary layer effect (Kannan and Sundaram, 2001). The deviation of plots from the origin (Fig. 6) may be due to the difference between the rate of mass transfer in the initial and final stages of adsorption. Furthermore, such deviation of a straight line from the origin indicates that the pore diffusion is not the sole ratecontrolling step (Poots et al., 1978) as shown earlier in Bangham's equation. From Fig. 7, it may be seen that there are two separate regions - the initial portion is attributed to bulk diffusion and the linear portion to intra-particle diffusion (Allen et al., 1989) and the temperature has no significant effect on the adsorption capacity of SW in the range of 30 to $50^{\circ} \mathrm{C}$.

The experimental data obtained in the present study can be used for designing a large scale batch adsorption system for the removal of dyes from aqueous solution. In order to achieve a desirable removal of $\mathrm{MB}$, the amount of adsorbent to be added and the residence time of the liquid in the batch need to be determined (Dang et al., 2009). For a given equilibrium concentration, $\mathrm{C}_{\mathrm{e}}$, the amount of $\mathrm{MB}$ adsorbed onto the adsorbent at equilibrium, $\mathrm{q}_{\mathrm{e}}$, can be estimated from the Langmuir isotherm model. The required amount of adsorbent, $m_{D}$, to treat a volume of liquid, $\mathrm{V}_{\mathrm{D}}$, can then be calculated as below:

$\mathrm{m}_{\mathrm{D}}=\frac{\left(\mathrm{C}_{\mathrm{i}}-\mathrm{C}_{\mathrm{e}}\right) \mathrm{V}_{\mathrm{D}}}{\mathrm{q}_{\mathrm{e}}}$

where $C_{i}$ is the initial dye concentration in liquid.

The residence time of the liquid in the batch could then be estimated using the pseudo-secondorder kinetics obtained in the present study. The values of $\mathrm{q}_{\mathrm{e}}$ and $\mathrm{k}$ are already known. The amount of dye removed $\left(\mathrm{q}_{\mathrm{t}}\right)$ can be estimated as below:

$$
\mathrm{q}_{\mathrm{t}}=\frac{\left(\mathrm{C}_{\mathrm{i}}-\mathrm{C}_{\mathrm{t}}\right) \mathrm{V}_{\mathrm{D}}}{\mathrm{m}_{\mathrm{D}}}
$$

where $\mathrm{C}_{\mathrm{t}}$ is the specified dye concentration remaining in the liquid at the end of the adsorption cycle. The calculated value of $\mathrm{q}_{\mathrm{t}}$ can then be substituted into Eq. (13) for the pseudo-second-order kinetics to estimate the adsorption time, which is also the residence time of the liquid in the batch.

Table 8: Intra-particle diffusion parameters for the removal of $\mathrm{MB}$ by

\begin{tabular}{|c|c|c|c|}
\hline \multicolumn{4}{|c|}{ Intra-particle diffusion model } \\
\hline $\mathrm{C}_{0}\left(\mathrm{mg} \mathrm{L}^{-1}\right)$ & $k_{i d}\left(m g ~ g^{-1} \min ^{1 / 2}\right)$ & $I\left(\mathrm{mg} \mathrm{g}^{-1}\right)$ & $\mathbf{R}^{2}$ \\
\hline 25 & 0.0109 & 4.0035 & 0.74 \\
\hline 50 & 0.0477 & 7.7527 & 0.687 \\
\hline 75 & 0.1033 & 11.265 & 0.636 \\
\hline 100 & 0.1622 & 14.692 & 0.652 \\
\hline
\end{tabular}
$\mathrm{SW}\left(\mathrm{T}=303 \mathrm{~K}, \mathrm{C}_{0}=25,50,75\right.$ and $\left.100 \mathrm{mg} \mathrm{L}^{-1}, \mathrm{~m}=6 \mathrm{~g} \mathrm{~L}^{-1}\right)$.

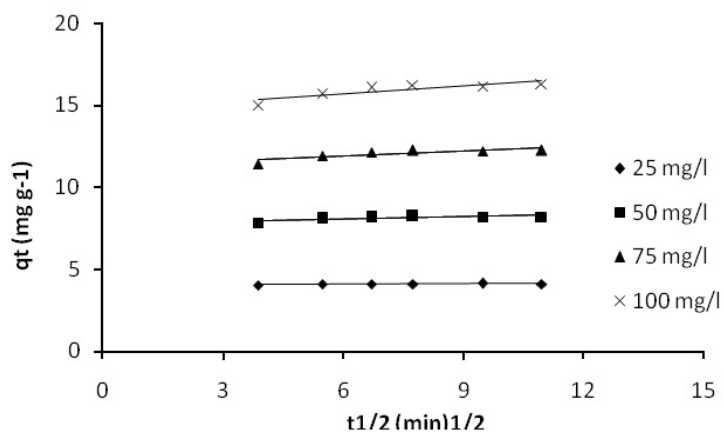

Figure 6: Intra-particle diffusion plot for the removal of $\mathrm{MB}\left(\mathrm{T}=303 \mathrm{~K}, \mathrm{C}_{\mathrm{o}}=25,50,75\right.$ and $\left.100 \mathrm{mg} \mathrm{L}^{-1}, \mathrm{~m}=6 \mathrm{~g} \mathrm{~L}^{-1}\right)$.

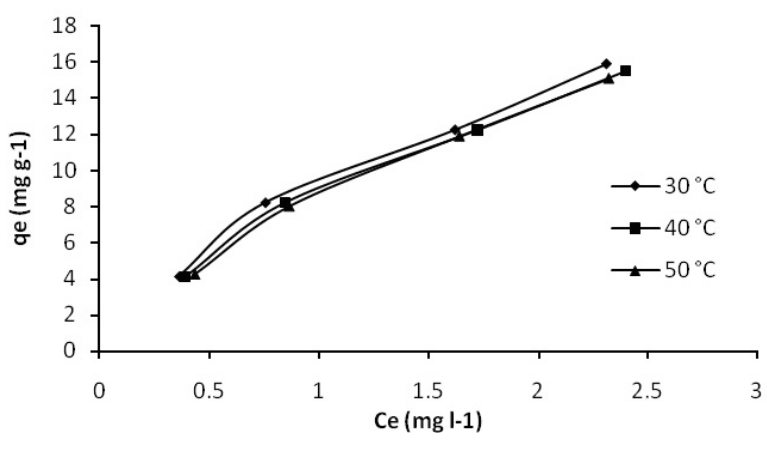

Figure 7: Equilibrium adsorption isotherms at different temperatures for $\mathrm{MB}-\mathrm{SW}$ system $(\mathrm{t}=3$ $\left.\mathrm{h}, \mathrm{m}=6 \mathrm{~g} \mathrm{~L}^{-1}\right)$. 
Table 9: Different error functions used for the error analysis of the kinetic data.

\begin{tabular}{|l|c|c|}
\hline \multicolumn{1}{|c|}{ Error Function } & Abbreviation & Formula \\
\hline $\begin{array}{l}\text { The sum of the } \\
\text { squares of the errors }\end{array}$ & SSE & $\sum_{\mathrm{i}=1}^{\mathrm{n}}\left(\mathrm{q}_{\mathrm{e}, \mathrm{cal}}-\mathrm{q}_{\mathrm{e}, \mathrm{exp}}\right)_{\mathrm{i}}^{2}$ \\
\hline $\begin{array}{l}\text { The sum of the } \\
\text { absolute errors }\end{array}$ & SAE & $\sum_{\mathrm{i}=1}^{\mathrm{n}}\left|\mathrm{q}_{\mathrm{e}, \mathrm{cal}}-\mathrm{q}_{\mathrm{e}, \mathrm{exp}}\right|_{\mathrm{i}}$ \\
\hline The average relative error & ARE & $\frac{100}{\mathrm{n}} \sum_{\mathrm{i}=1}^{\mathrm{n}}\left|\frac{\mathrm{q}_{\mathrm{e}, \text { exp }}-\mathrm{q}_{\mathrm{e}, \mathrm{cal}}}{\mathrm{q}_{\mathrm{e}, \mathrm{exp}}}\right|_{\mathrm{i}}$ \\
\hline
\end{tabular}

Table 10: Different error analyses of isotherm models for adsorption of $\mathrm{MB}$ by $\mathrm{SW}\left(t=1.5 \mathrm{~h}, C_{0}=25,50\right.$, 75 and $\left.100 \mathrm{mg} \mathrm{l}^{-1}, m=6 \mathrm{~g} \mathrm{~L}^{-1}\right)$.

\begin{tabular}{|c|c|c|c|c|}
\hline Error Function & Langmuir & Freundlich & Temkin & D-R \\
\hline \multicolumn{5}{|c|}{$\mathbf{3 0 3 ~ K}$} \\
\hline SSE & 0.49 & 0.38 & 0.29 & 4.13 \\
SAE & 0.97 & 1.07 & 2.98 & 3.39 \\
ARE & 2.25 & 3.16 & 2.05 & 7.39 \\
\hline SSE & 1.19 & 0.57 & 2.45 & 7.29 \\
SAE & 1.56 & 1.29 & 2.98 & 4.44 \\
ARE & 3.11 & 3.53 & 3.03 & 9.88 \\
\hline SSE & 0.64 & 9.99 & 2.00 & 1.45 \\
SAE & 1.34 & 5.17 & 2.27 & 1.86 \\
ARE & 3.19 & 11.6 & 5.35 & 5.01 \\
\hline
\end{tabular}

\section{Error Analysis}

Three different error functions, i.e., the sum of squares of the errors (SSE), sum of the absolute errors (SAE) and average relative error (ARE) were employed to find out the most suitable kinetic and isothermal model to represent the experimental data. Table 9 shows different error functions. Error analyses of isotherm models for adsorption of MB by MOC are represented in Table 10.

From the results of the error functions, it is found that the adsorption process follows different isotherms at different temperatures. The data fits best to the Temkin model at $303 \mathrm{~K}$, to the Freundlich model at $313 \mathrm{~K}$ and to the Langmuir model at $323 \mathrm{~K}$.

\section{CONCLUSION}

The present study explores the efficiency of solid waste obtained from the biodiesel plant as an adsorbent for the removal of $\mathrm{MB}$ from aqueous solution. The adsorption process was found to be dependent on initial $\mathrm{pH}$, dye concentration, adsorbent dose, contact time and temperature of the process. The experimental data were compared by fitting to various adsorption isotherms such as Langmuir, Freundlich, Temkin and D-R isotherms. On the basis of these data, respective constants of different isotherms and thermodynamic parameters were calculated. Negative values of Gibb's free energy $\left(\Delta \mathrm{G}^{0}\right)$ indicate the spontaneity of the adsorption process, whereas, the negative values of change in enthalpy $\left(\Delta \mathrm{H}^{\circ}\right)$ and positive change in entropy $\left(\Delta S^{\circ}\right)$ indicates the endothermic nature and increased randomness of the ongoing process, respectively. Kinetics of the adsorption was also monitored and it was found that the process follows pseudo-second-order kinetics. The kinetic studies revealed that initially the adsorption process of MB over MOC followed bulk diffusion and then shifted to intra-particle diffusion. Eqs. (17) and (18) can be applied to the data obtained from pseudosecond-order kinetics for the design of a large scale batch adsorption of $\mathrm{MB}-\mathrm{SW}$ system.

\section{NOMENCLATURE}

b energy related constant

$\mathrm{b}_{1}, \mathrm{~b}_{2} \quad$ equilibrium constants

$\mathrm{B}_{1} \quad$ constant related to heat of adsorption 


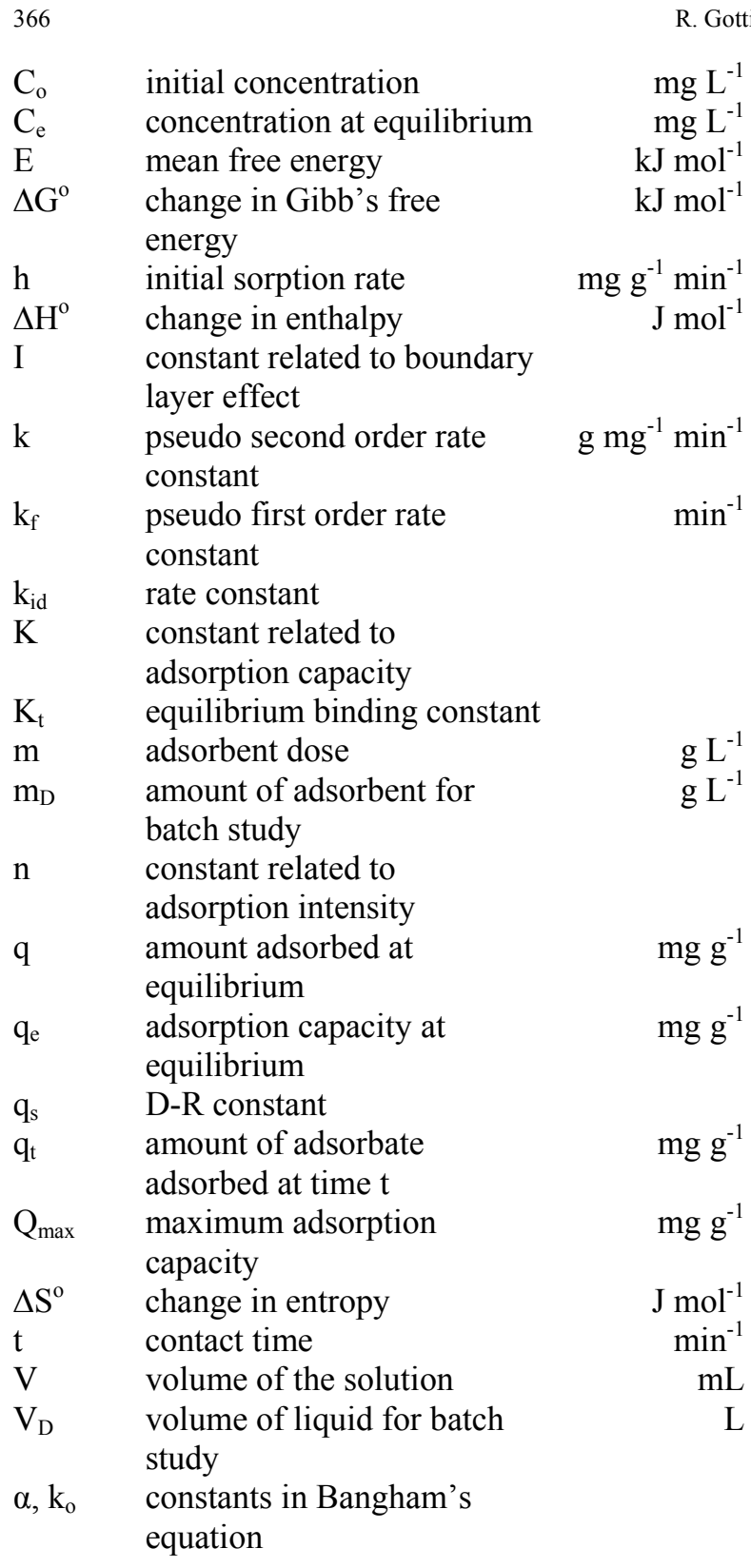

\section{REFERENCES}

Aharoni, C., Sideman, S., Hoffer E., Adsorption of phosphate ions by colloid ion coated alumina. Journal of Chemical Technology and Biotechnology, 29, 404-12 (1979).

Allen, S. J., Koumanova, B., Decolourisation of water/wastewater using adsorption. Journal of the University of Chemical Technology and Metallurgy, 40, 175-192 (2003).

Allen, S. J., Mckay, G., Khader, K. Y. H., Intraparticle diffusion of a basic dye during adsorption onto sphagnum peat. Environmental Pollution, 56, 39-50 (1989).
Al-Qodah, Z., Lafi, W.K., Al-Anber, Z., AlShannag., Harahsheh, A., Adsorption of methylene blue by acid and heat treated diatomaceous silica. Desalination 217, 212-224 (2007).

Alzaydien, A. S., Adsorption of methylene blue from aqueous solution onto a low-cost natural jordanian Tripoli. American Journal of Environmental Sciences, 5, 197-208 (2009).

Bello, O. S., Adeogun, I. A., Ajaelu, J. C., Fehintola EO. Adsorption of methylene blue onto activated carbon derived from periwinkle shells: kinetics and equilibrium studies. Chemistry and Ecology, 24, 285-295 (2008).

Bhattacharyya, K.G., Sharma, A., Kinetics and thermodynamics of methylene blue adsorption on Neem (Azadirachta indica) leaf powder. Dyes and Pigments 65, 51-59 (2005).

Bilal, A., Adsorption of Congo red from aqueous solution onto calcium-rich fly ash. Journal of Colloid and Interface Science, 274, 371-379 (2004).

Brown, D., Effects of colorants in the aquatic environment. Ecotoxicology and Environmental Safefy, 13, 139-147 (1987).

Cengiz, S., Cavas, 1., Removal of methylene blue by invasive marine seaweed: Caulerpa racemosa var. cylindracea. Bioresource Technology 99, 2357-63 (2008).

Daneshvar, N., Ayazloo, M., Khataee, A. R., Pourhassan, M., Biological decolorization of dye solution containing Malachite Green by microalgae Cosmarium sp. Bioresource Technology, 98, 1176-1182 (2007).

Dang, V. B. H., Doan, H. D., Dang-Vu, T., Lohi, A., Equilibrium and kinetics of biosorption of cadmium(II) and copper(II) ions by wheat straw. Bioresource Technology 100, 211-219 (2009).

Dogan, M., Alkan, M., Turkyilmaz, A., Özdemir, O. Y., Kinetics and mechanism of removal of methylene blue by adsorption onto perlite. Journal of Hazardous Materials B 109, 141-148 (2004).

Dubinin, M. M., Radushkevich, L.V., Equation of the characteristic curve of activated charcoal. Chemie in unserer Zeit, 1, 875 (1947).

Dursun, O., Giilgeyi, D., Ahmet, O., Methylene blue adsorption from aqueous solution by dehydrated peanut hull. Journal of Hazardous Materials, 144, 171-179 (2007).

EI-Qada, E. N., Allen, S. J., Walker, G. M., Adsorption of basic dyes from aqueous solution onto activated carbons. Chemical Engineering Journal, 135, 174-184 (2008). 
Ghosh, D., Bhattacharyya, K. G., Adsorption of methylene blue on kaolinite. Applied Clay Science, 20, 295-300 (2002).

Gupta, V. K., Mittal, A., Jain, R., Mathur, M., Sikarwar, S., Adsorption of Safranin-T from waste water using waste materials - activated carbon and activated rice husks. Journal of Colloid and Interface Science, 303, 80-86 (2006).

Hamdaoui, O., Batch study of liquid-phase adsorption of methylene blue using cedar sawdust and crushed brick. Journal of Hazardous Materials, B 135, 264-273 (2006).

Hasany, H. M., Chaudhary, M. H., Sorption potential of Hare river sand for the removal of antimony from acidic aqueous solution. Applied Radiation and Isotopes 47, 467-71 (1996).

Ho, Y. S., McKay, G., Pseudo-second order model for sorption processes. Process Biochemistry 34, 451-65 (1999).

Ho, Y. S., McKay, G., The kinetics of sorption of basic dyes from aqueous solutions by sphagnum moss peat. Canadian Journal of Chemical Engineering, 76, 822-826 (1998).

Hubbard, A. T., Ed., Encyclopedia of Surface and Colloid Science. Marcel Dekker Inc., New York (2001).

Kannan, K., Sundaram, M. M., Kinetics and mechanism of removal of methylene blue by adsorption on various carbons e a comparative study. Dyes Pigments, 51, 25-40 (2001).

Kim, Y., Kim, C., Choi, I., Rengraj, S., Yi, J., Arsenic removal using mesoporous alumina prepared via a templating method. Environmental Science and Technology, 38, 924-31 (2004).

Lagergren, S., About the theory of so called adsorption of soluble substances. Ksver Veterskapsakad Handl, 24, 1-6 (1898).

MacKay, G., Allen, S. J., Surface mass transfer process using peat as an adsorbent for dyestuffs. Canadian Journal of Chemical Engineering, 58, 521-526 (1980).

Mishra, S., Prakash, D. J., Ramakrishna, G., Characterization and utilization of mahua oil cake - A new adsorbent for the removal of congored dye from aqueous phase. Electronic Journal of Environmental, Agricultural and Food Chemistry, 8, 425-436 (2009).

Mission, M., Haron, R., Kamaroddin, M. F. A., Amin, N. A. S., Pretreatment of empty palm fruit bunch for production of chemicals via catalytic pyrolysis. Bioresource Technology, 100, 28672873 (2009).

Mittal, A., Kaur, D., Mittal, J., Applicability of waste materials-bottom ash and deoiled soya-as adsorbents for the removal and recovery of a hazardous dye - brilliant green. Journal of Colloid and Interface Science, 326, 8-17 (2008).

Namasivayam, C., Kavitha, D., Removal of Congo Red from water by adsorption onto activated carbon prepared from coir pith, an agricultural solid waste. Dyes and Pigments 54, 47-58 (2002).

Perrich, R., Activated Carbon Adsorption for Wastewater Treatment. CRC Publishers Inc., Boca Raton, Florida, USA (1981).

Poots, V. J. P., McKay, G., Healy, J. J., Removal of basic dye from effluent using wood as an adsorbent. Journal of Water Pollution Control Federation, 50, 926-39 (1978).

Purkait, M. K., Maiti, A., Das Gupta, S., De, S., Removal of congo red using activated carbon and its regeneration. Journal of Hazardous Materials, 145, 287-295 (2007).

Sricharoenchaikul, V., Pechyen, C., Aht-ong, D., Atong, D., Preparation and characterization of activated carbon from the pyrolysis of physic nut (Jatropha curcas L.) waste. Energy and Fuels, 22, 31-37 (2008).

Temkin, M. J., Pyzhev, V., Recent modification to Langmuir isotherms. Acta Physicochimca URSS, 12, 217-25 (1940).

Thakkar, A. L., Wilham, W. L., Zografi, G., Adsorption of methylene blue by potato starch: Effect of methanol, dioxane, sucrose, and urea in aqueous systems. Journal of Pharmaceutical Sciences, 59, 1466-1470 (1970).

Tutem, E., Apak, R., Unal, C. F., Adsorptive removal of chlorophenols from water by bituminous shale. Water Research, 32, 2315-24 (1998).

Wang, S., Li, L., Wu, H., Zhu, Z. H., Unburned carbon as a low-cost adsorbent for treatment of methylene blue-containing wastewater. Journal of Colloid and Interface Science, 292, 336-343 (2005).

Weber, Jr., W. J., Morris, J. C., Kinetics of adsorption on carbon from solution. Journal of Sanitary Engineering Division ASCE, 89, 31-59 (1963). 